\title{
Correction to: Vasomodulatory effects of the angiotensin II type 1 receptor antagonist losartan on experimentally induced cerebral vasospasm after subarachnoid haemorrhage
}

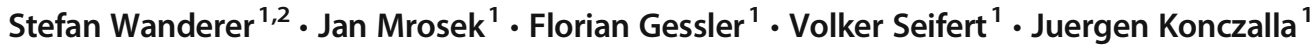

Published online: 22 December 2017

(C) Springer-Verlag GmbH Austria, part of Springer Nature 2017

\section{Correction to: Acta Neurochirurgica} https://doi.org/10.1007/s00701-017-3419-2

The original version of this paper unfortunately captured the names of Florian Gessler and Volker Seifert incorrectly and are now corrected in this paper.

The original article has been corrected.

The online version of the original article can be found at https://oi.org/ 10.1007/s00701-017-3419-2.

Stefan Wanderer

stefan.wanderer@ksa.ch

1 Department of Neurosurgery, Goethe-University Hospital, Frankfurt am Main, Germany

2 Department of Neurosurgery, Kantonsspital Aarau, Tellstrasse 25, 5001 Aarau, Switzerland 